\title{
CORN OIL REMOVAL BY ADVANCED OXIDATION PROCESSES IN COMPARTION WITH CASTOR AND COCONUT OILS
}

\author{
${ }^{*}$ Nada S. Joodi ${ }^{1}$
}

Nagam O. Kariem 1

1) Environmental Engineering Department, College of Engineering, Mustansiriyah University, Baghdad, Iraq

\begin{abstract}
The AOPs advanced oxidation process has been studied in three ways: $\left(\mathrm{UV} / \mathrm{H}_{2} \mathrm{O}_{2}\right)$, Fenton, and PhotoFenton in artificial water treating from vegetable oils. The corn, castor, and coconut oils emulsion were prepared and treated by AOPs. Several variables were studied: time, $\mathrm{pH}$, mixing speed, temperature, the dose of chemicals $\left(\mathrm{H}_{2} \mathrm{O}_{2} \& \mathrm{Fe}_{2} \mathrm{SO}_{4} .7 \mathrm{H}_{2} \mathrm{O}\right)$, and finally the oil concentration. The best conditions were obtained in several experiments where the Fenton and Photo-Fenton process operates in an acidic medium $(\mathrm{pH}=3.5)$, while the $\mathrm{UV} / \mathrm{H}_{2} \mathrm{O}_{2}$ process operates with the neutral medium $(\mathrm{pH}=7)$. The optimum temperature for the Photo-Fenton and $\mathrm{UV} / \mathrm{H}_{2} \mathrm{O}_{2}$ processes is $40^{\circ} \mathrm{C}$, and for the Fenton process is $20^{\circ} \mathrm{C}$. While there was an effect of mixing speed, higher efficiency was achieved at $(1000 \mathrm{rpm})$ for the PhotoFenton process and $(500 \mathrm{rpm})$ for the Fenton and $\mathrm{UV} / \mathrm{H}_{2} \mathrm{O}_{2}$ processes. Also, the $\mathrm{H}_{2} \mathrm{O}_{2}$ concentration was at $(500 \mathrm{mg} / \mathrm{L})$ for all processes, when the $\mathrm{Fe}_{2} \mathrm{SO}_{4} .7 \mathrm{H}_{2} \mathrm{O}$ concentration for the photo-Fenton process $=(50 \mathrm{mg} / \mathrm{L})$, and for the Fenton process $=(250 \mathrm{mg} / \mathrm{L})$. Oil concentration $=(1750 \mathrm{mg} / \mathrm{L})$. Optimum conditions were applied to treat vegetable oils, the Fenton process gave a maximum removal efficiency of 95.2\% for corn oil (COD 12800 to $610 \mathrm{mg} / \mathrm{L}$ ), $94.5 \%$ for castor oil, while $57.5 \%$ for coconut oil after the total reaction time (180 minutes). The Photo-Fenton process gave removal efficiencies: 93\% for corn oil (COD 12500 to $870 \mathrm{mg} / \mathrm{L}$ ), $83.8 \%$ for castor oil, and $61.6 \%$ for coconut oil. The UV/ $\mathrm{H}_{2} \mathrm{O}_{2}$ process gave removal efficiencies: $69.8 \%$ for corn oil, $32 \%$ for castor oil, and $23.4 \%$ for coconut oil after the total irradiation time. As real wastewater, the treatment was acceptable and achieved an efficiency of $44.7 \%, 89.2 \%$, and $83.8 \%$ for the $\mathrm{UV} / \mathrm{H}_{2} \mathrm{O}_{2}$, Fenton, and Photo-Fenton processes, respectively.
\end{abstract}

Keywords: Corn Oil, Advanced Oxidation Process, $\mathrm{UV} / \mathrm{H}_{2} \mathrm{O}_{2}$, Fenton, Photo-Fenton, Castor oil, Coconut oil

\section{Introduction}

The development of the world with agriculture, industries, and urban development leads to an increase in the pollutants generated from them that are disposed of in natural waters, giving increasing attention to methods of effective treatment and protection of surface and groundwater. A good strategy involves treating sewage before dumping it into the river with a technically and economically efficient technique, in which the mechanism is studied on relatively small amounts of toxic and persistent organic matter, to be applied in decontamination of large quantities of natural water and its complex pollutants. In this paper, AOPs are demonstrated to be highly effective technologies for treating industrial water and wastewater. As evidence of this, over the past two decades, there has been a growing interest in studies on the mechanisms and applications of AOPs in wastewater treatment [1].

(AOPs) were precisely identified in 1987 by Glaze et al. that would occur under normal conditions [2]. With increasing research and applied for work as successful and environmentally friendly ways to remove pollutants. AOPs have become an extensive tree

*Corresponding Author: nada_judy@yahoo.com 
of processes that depend on the formation of hydroxyl radicals through chemical, photochemical, or electrochemical reactions $[3,4]$. One of the oldest and most widely used Fenton methods is the one that relies on soluble iron(II) salt and $\mathrm{H}_{2} \mathrm{O}_{2}$, commonly known as Fenton reagent, to decompose and destroy POPs, irradiation can be added to the Fenton method to simultaneously treat the water sample by UV To be the so-called Photo-Fenton [5].

\section{Materials and Methods}

\subsection{Materials}

Commercial corn oil was used as a contaminated sample of edible vegetable oil. Other types of vegetable oils were used in health or cosmetics, namely castor and coconut oils.

The materials used required for this study are:

1. Sodium Dodecyl Sulfate, SDS $\left(\mathrm{C}_{12} \mathrm{H}_{25} \mathrm{Na}_{4} \mathrm{~S}\right)$ (Beltric, Spain)

2. Ferrous Sulfate $\left(\mathrm{FeSO}_{4} \cdot 7 \mathrm{H}_{2} \mathrm{O}\right)$ from Hopkin and Williams (England),

3. Hydrogen Peroxide $\left(\mathrm{H}_{2} \mathrm{O}_{2}\right)(50 \%$, w/w) from Solvochem

4. Sodium Thiosulfate $\left(\mathrm{Na}_{2} \mathrm{~S}_{2} \mathrm{O}_{3}\right)$ from Central Drug House (India)

5. $\mathrm{NaOH}$ and $\mathrm{H}_{2} \mathrm{SO}_{4}$ to achieve the desired pH Central Drug House (P) Ltd. (India).

\subsection{Methods}

The advanced oxidation process (AOPs) were used three methods: $\mathrm{UV} / \mathrm{H}_{2} \mathrm{O}_{2}$, Fenton, and Photo-Fenton. All the reagents used in the experiments for the above methods were hydrogen peroxide, $\mathrm{H}_{2} \mathrm{O}_{2}$, ferrous sulfate, $\mathrm{FeSO}_{4} \cdot 7 \mathrm{H}_{2} \mathrm{O}$.

The experiments were performed in the Health Laboratory in batch form, (Fig. 1), the reactor consisted of a $2 \mathrm{~L}$ glass beaker placed on a magnetic stirrer with a heater (HTS-1003/HTP1002/MGS-1001, BOECO, Germany).
Ultraviolet radiation $(254 \mathrm{~nm})$ was generated from UV lamps (TUV 11W 4P-SE, Philips, England), which were installed vertically at the top of the reactor. The distance between the lamp and the reactor was $5 \mathrm{~cm}$ to ensure more absorption as mentioned [7]. The lamp is completely submerged in the reactor and then encased by a quartz sleeve for protection.

\subsection{Experimental}

An emulsion (oil-water) was prepared as a sample of artificial water from the used oils using an SDS emulsifying agent by taking $(2.5 \mathrm{ml})$ of $(100 \mathrm{mg} / \mathrm{L})$ sodium dodecyl sulfate per liter of distilled water and gradually adding $(100 \mathrm{ml})$ oil. With rapid mixing at (2000 rpm.) for 48 hours [6].

The required volume of the prepared and stored emulsion, which corresponds to the specified oil concentration in each experiment, is taken within the range (1000-2500) $\mathrm{mg} / \mathrm{l}$ through dilution with distilled water represented in equation (1):

$V 1 \times C 1=V 2 \times C 2$

Where:

$\mathrm{V}_{1}=$ Stock Volume $(\mathrm{L})$

$\mathrm{V}_{2}=$ Required Volume $(\mathrm{L})$

$\mathrm{C}_{1}=$ Stock Concentration $(\mathrm{mg} / \mathrm{l})$

$\mathrm{C}_{2}=$ Required Concentration $(\mathrm{mg} / \mathrm{l})$

\subsection{Analysis}

The chemical oxygen order is approved to check the removal percentage of the samples and the assay is using two devices: The first is a 120minute COD thermal reactor at $150{ }^{\circ} \mathrm{C}$ commercially available digestion solution (COD test kit) in three ranges; Heart rate range (015000) $\mathrm{mg} / \mathrm{L}$, MR range: (0-1500) $\mathrm{mg} / \mathrm{L}, \mathrm{LR}$ range: $(0-150) \mathrm{mg} / \mathrm{L}$. The second device is Lovibond Checkit (Germany) direct COD photometer. The COD concentration reading is colorimetrically measured at $605 \mathrm{~nm}$., And then assessing the removal efficiency: 
COD Removal efficiency $\%=\frac{\mathrm{COD}_{\mathrm{i}}-\mathrm{CODf}}{\mathrm{COD}_{\mathrm{i}}} * 100$

Where:

$\mathrm{COD}_{\mathrm{i}}=$ Initial $\mathrm{COD}$ concentration prior to treatment $(\mathrm{mg} / \mathrm{L})$

$\operatorname{COD} f=$ Final $\mathrm{COD}$ concentration after treatment $(\mathrm{mg} / \mathrm{L})$

\section{Results and Discussion}

\subsection{The Effect of Reaction Time}

The effect of the time required for 4 hours of treatment was studied to obtain the best clearance for all operations, the initial amount of $\mathrm{H}_{2} \mathrm{O}_{2}$, $\mathrm{Fe}_{2} \mathrm{SO}_{4} .7 \mathrm{H}_{2} \mathrm{O}$, pH, Mixing Speed, and the temperature was determined. The concentration of primary corn oil was $(1750 \mathrm{mg} / \mathrm{L})$. As in Fig. (2), with increasing time, the dissociation of the pollutant increases and the reaction reaches beyond carbon dioxide, and thus the efficiency increases. Results are approximate [8].

\subsection{The Effect of $\mathrm{pH}$}

Many $\mathrm{pH}$ values (3.5, 7, and 10.5) were examined with the other parameters being kept constant for 180 min. In Fig. 4, for the UV/ $\mathrm{H}_{2} \mathrm{O}_{2}$ process, the value of removal efficiency was (40.3\%) at $\mathrm{pH}=7$, and the efficiency was also acceptable at $\mathrm{pH}=3.5$, equal to $(39.4 \%)$. While the efficiency values for Photo-Fenton and Fenton are (89.5\%) and (16.9\%), respectively, at $\mathrm{pH}=3.5$. Note that the Fenton-Fenton reaction occurs in a similar acidic medium (Sohrabi and Khavaran, 2014). The $\mathrm{UV} / \mathrm{H}_{2} \mathrm{O}_{2}$ reaction is in a neutral or acidic medium, similar [9].

\subsection{The effect of Mixing Speed}

Mixing speed $(1500,1000,500)$ rpm. was checked by magnetic motor control. Fig. 4 shows that the removal efficiency is affected by different speeds, as the two processes $\mathrm{UV} / \mathrm{H}_{2} \mathrm{O}_{2}$ and Fenton were at a mixing speed of $500 \mathrm{rpm}$., Close to the study [10]. In $\mathrm{UV} / \mathrm{H}_{2} \mathrm{O}_{2}$ the value of removal efficiency is $(55.4 \%)$ because it achieves a stoichiometric absorption of UV rays per particle. The Fenton process has an efficiency $(49.3 \%)$ that the slow mixing determines the time required for the reaction compared to the high speed that helps generate the hydroxyl radicals, which in turn accelerates the advanced oxidation process. For the same reason, for the Photo Fenton process, the removal efficiency was approximate and acceptable for medium and slow mixing because it combines the two processes mentioned above, and thus the efficiency was $(84.6 \%)$ at $500 \mathrm{rpm} .,(96.7 \%)$ at (1000 rpm.).

\subsection{The Effect of $\mathrm{H}_{2} \mathrm{O}_{2}$ Concentration}

The effect of concentration of $\mathrm{H}_{2} \mathrm{O}_{2}$ is studied with multiple choice of concentrations. The relationship between removal efficiency and $\mathrm{H}_{2} \mathrm{O}_{2}$ concentrations is fluctuating, because peroxide is the basis of the advanced oxidation process and is the generator of the hydroxyl radical. It was observed through this experiment that the optimum peroxide concentration is 500 $\mathrm{mg} / 1$ similar [11]. Fig. 5 shows at $500 \mathrm{mg} / \mathrm{L}$ the maximum removal efficiency of $(69 \%),(77.2 \%)$, and $(91.7 \%)$ reduction of $\mathrm{COD}$ by $\mathrm{UV} / \mathrm{H}_{2} \mathrm{O}_{2}$, Fenton, and Photo-Fenton, respectively. It causes a greater amount of hydroxyl radicals to be generated and they quickly combine to form stable atoms again, which reduces its presence as a free radical and thus reduces oxidation. . At higher $\mathrm{H}_{2} \mathrm{O}_{2}$ concentrations, lower light intensity is available for oil degradation, since $\mathrm{H}_{2} \mathrm{O}_{2}$ is also slightly absorbed into the system [12].

\subsection{The effect of $\mathrm{Fe}_{2} \mathrm{SO}_{4} .7 \mathrm{H}_{2} \mathrm{O}$ Concentration}

The effect of $\left(\mathrm{Fe}_{2} \mathrm{SO}_{4} .7 \mathrm{H}_{2} \mathrm{O}\right)$ on Fenton and Photo-Fenton processes was tested by running experiments with different concentrations. . Fig. 6 shows the efficiency increases with increasing amounts of iron salt $\left(\mathrm{Fe}^{++}\right)$. For the Fenton process, when the sulfate concentration (250 
$\mathrm{mg} / \mathrm{L})$, the removal efficiency was (84.9\%). In the Photo-Fenton process, the efficiency reaches its maximum value $(86.9 \%)$ at the concentration of sulfate $(50 \mathrm{mg} / \mathrm{L})$ as in a study [13].

\subsection{The Effect of Oil Concentration}

In Fig. 7, it can be seen that the removal efficiency increases with higher oil concentrations, which range between (10002500) $\mathrm{mg} / \mathrm{l}$. The optimum efficiency was obtained at a concentration of $1750 \mathrm{mg} / \mathrm{l}$. In the $\mathrm{UV} / \mathrm{H}_{2} \mathrm{O}_{2}$ process, the efficiency is $31.4 \%$ and $30.9 \%$ at oil concentrations (1750) and (2500) $\mathrm{mg} / \mathrm{L}$ respectively. In the Fenton process, the efficiency is highest at $96.8 \%(1750 \mathrm{mg} / \mathrm{L})$. In the Photo-Fenton process, the efficiency is $83.4 \%$ at the same concentration, so the higher COD reduction is when the oil is concentrated to 1750 $\mathrm{mg} / \mathrm{l}$, and it decreases when the concentrations increase because the turbidity in the solution results from the increase in concentrations of Hinder curing and absorption of UV rays.

\subsection{Type of Vegetable Oils}

The optimum conditions obtained from the above experiments are applied to other types of vegetable oils instead of corn oil, such as castor oil and coconut oil. Table (1) shows the results for treating three types of oils with advanced oxidation, For $\mathrm{UV} / \mathrm{H}_{2} \mathrm{O}_{2}$ removal efficiency of corn oil was $69.8 \%$, castor oil was $32 \%$, and coconut oil $23.3 \%$ had a lower removal efficiency than other oils. As for the Fenton process, the efficiency was $95.2 \%, 94.5 \%$, and $57.5 \%$ for corn oil, castor oil, and coconut oil respectively. Whereas for the Photo-Fenton were $93.04 \%, 83.85 \%$, and $61.67 \%$, respectively.
Table 1. The COD Removal Efficiency of Types of Oil in Artificial Water by Photo-Fenton, Fenton Processes

\begin{tabular}{lccc}
\hline Type of & \multicolumn{3}{c}{ COD Removal Efficiency (\%) } \\
Oil & $\mathrm{UV} / \mathrm{H}_{2} \mathrm{O}_{2}$ & Photo- Fenton & Fenton \\
\hline Corn Oil & 69.8 & 93.04 & 95.2 \\
Castor Oil & 32 & 83.9 & 94.5 \\
Coconut Oil & 23.3 & 61.7 & 57.5 \\
\hline
\end{tabular}

The treatment was also applied to a real sample of wastewater of Al-Rasheed Factory, where a dilute volume was taken to obtain a concentration $(1750 \mathrm{mg} / \mathrm{L})$ and a treatment for 180 minutes, and the removal efficiency was obtained $44.7 \%$, $89.2 \%, 45.5 \%$ in $\mathrm{UV} / \mathrm{H}_{2} \mathrm{O}_{2}$. And Fenton and Photo-Fenton, respectively.

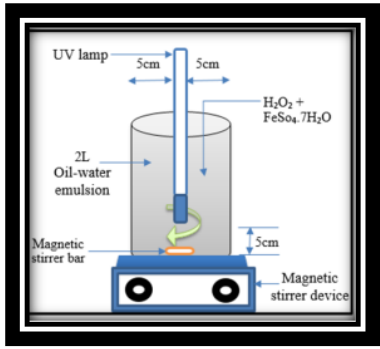

(A)

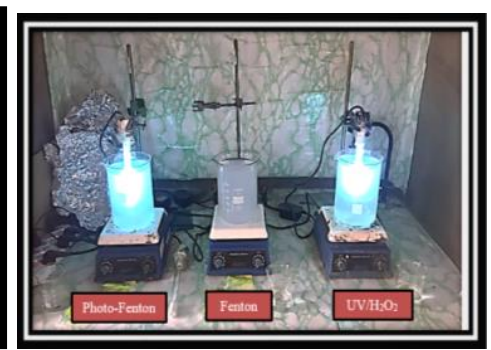

(B)
Figure 1. (A) Scale batch reactor (B) Laboratory unit scale batch reactor

\section{optimum time}

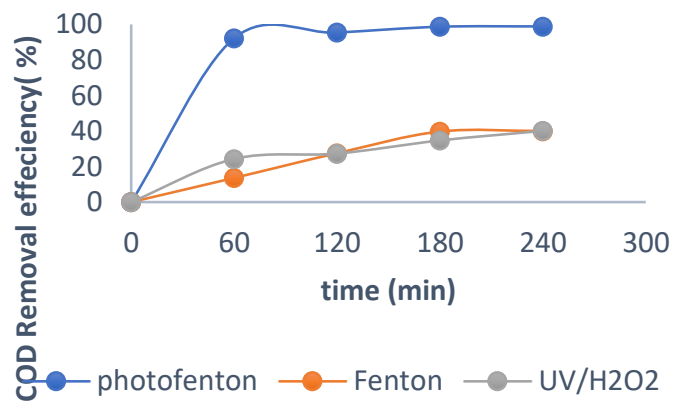

Figure 2. Effect of reaction time on the COD reduction of corn oil in artificial wastewater by Photo-Fenton, Fenton, and $\mathrm{UV} / \mathrm{H}_{2} \mathrm{O}_{2}$ processes 


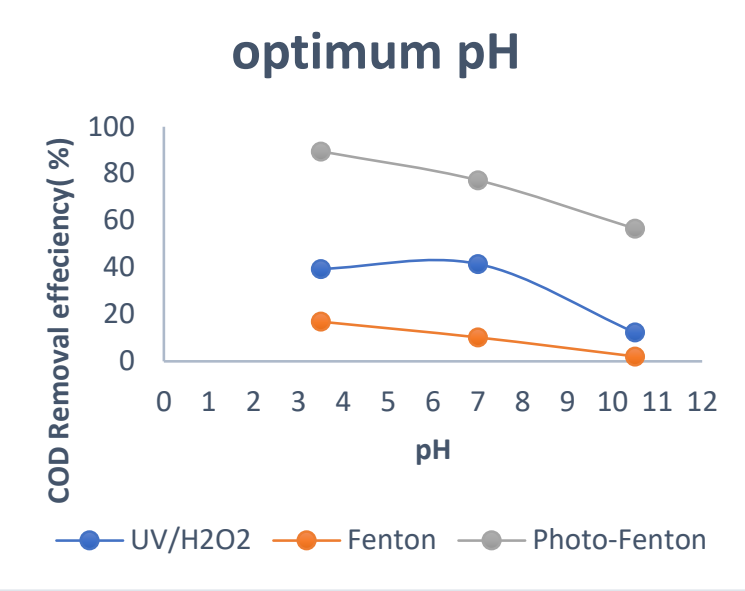

Figure 3. Effect of $\mathrm{pH}$ value on the COD reduction of corn oil in artificial wastewater by Photo-Fenton,

Fenton, and $\mathrm{UV} / \mathrm{H}_{2} \mathrm{O}_{2}$ processes

\section{optimum mixing speed}

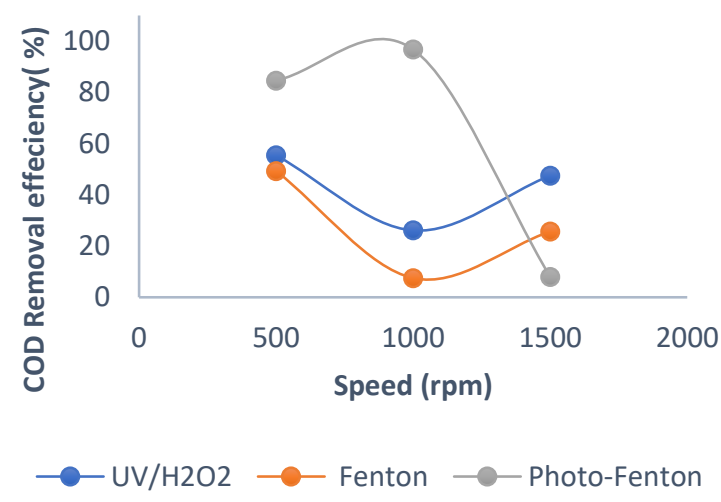

Figure 4. Effect of mixing speed on the COD reduction of corn oil in artificial wastewater by Photo-Fenton,

Fenton, and $\mathrm{UV} / \mathrm{H}_{2} \mathrm{O}_{2}$ processes

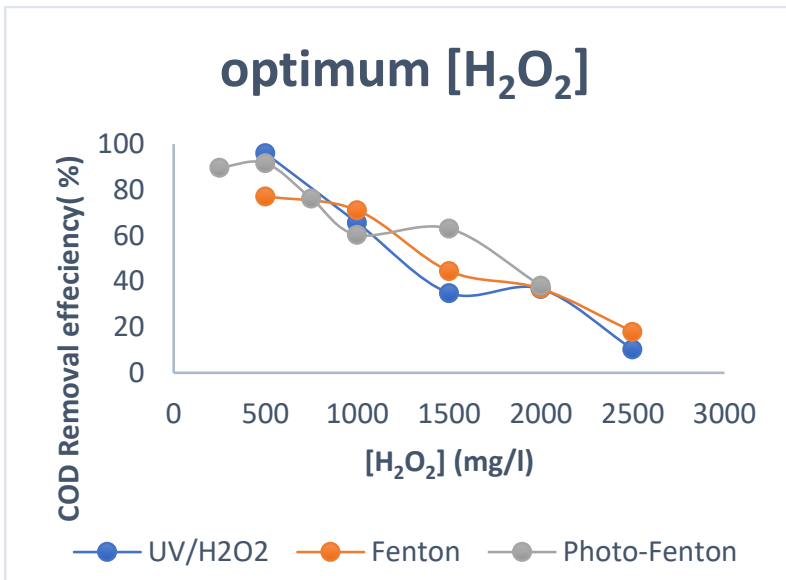

Figure 5. Effect of $\mathrm{H}_{2} \mathrm{O}_{2}$ concentration on the COD reduction of corn oil in artificial wastewater by PhotoFenton, Fenton, and $\mathrm{UV} / \mathrm{H}_{2} \mathrm{O}_{2}$ processes

\section{optimum $\left[\mathrm{Fe}_{2} \mathrm{SO}_{4} \cdot 7 \mathrm{H}_{2} \mathrm{O}\right]$}

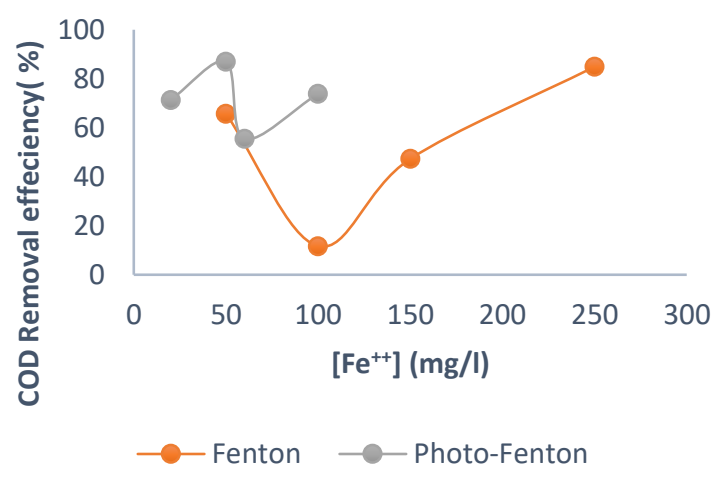

Figure 6. Effect of $\mathrm{Fe}_{2} \mathrm{SO}_{4} .7 \mathrm{H}_{2} \mathrm{O}$ concentration on the COD reduction of corn oil in artificial wastewater by Fenton and Photo-Fenton processes

\section{optimum Oil conc.}

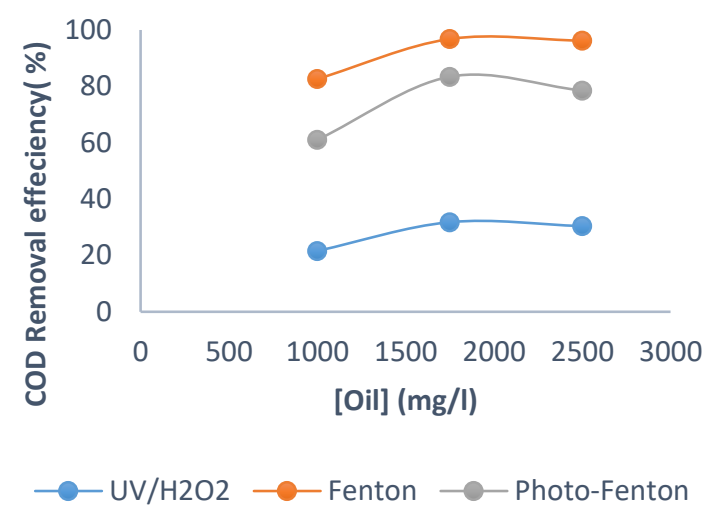

Figure 7. Effect of oil concentration on the COD reduction of corn oil in artificial wastewater by Fenton and Photo-Fenton processes

\section{Conclusions}

Some of an important conclusions discovered of this study are as follows:

- Advanced oxidation breaks down vegetable oils such as corn oil, castor oil, and coconut oil with processes (Fenton, Photo-Fenton, and $\mathrm{UV} / \mathrm{H}_{2} \mathrm{O}_{2}$ ).

- The best conditions for UV/H2O2 system are: time $=180$ minutes, $\mathrm{pH}=7$, mixing speed $=(500 \mathrm{rpm}$.$) , Temperature =40^{\circ} \mathrm{C}$, $\left[\mathrm{H}_{2} \mathrm{O}_{2}\right]=500 \mathrm{mg} / \mathrm{L}$ and $[$ oil $]=1750 \mathrm{mg} / \mathrm{L}$. 
- The best conditions for Fenton oxidation of wastewater are performed under specified operating conditions: time $=180$ minutes, $\mathrm{pH}=3.5$, mixing speed $=(500 \mathrm{rpm}$.$) ,$ Temperature $=20^{\circ} \mathrm{C},\left[\mathrm{H}_{2} \mathrm{O}_{2}\right]=500 \mathrm{mg} / \mathrm{L}$, $\left[\mathrm{Fe}_{2} \mathrm{SO}_{4} .7 \mathrm{H}_{2} \mathrm{O}\right]=250 \mathrm{mg} / \mathrm{L}$, [oil $]=1750$ $\mathrm{mg} / \mathrm{L}$.

- The best conditions for Photo-Fenton processes of artificial wastewater are performed under specified operating conditions: time $=180$ minutes, $\mathrm{pH}=3.5$, mixing speed $=(1000 \mathrm{rpm}$. $)$, Temperature $=$ $40^{\circ} \mathrm{C}, \mathrm{H}_{2} \mathrm{O}_{2}=500 \mathrm{mg} / \mathrm{L}, \mathrm{Fe}_{2} \mathrm{SO}_{4} .7 \mathrm{H}_{2} \mathrm{O}=50$ $\mathrm{mg} / \mathrm{L}$, oil concentration $=1750 \mathrm{mg} / \mathrm{L}$.

- The maximum oil degradation efficiency of artificial wastewater with corn oil for $\mathrm{UV} / \mathrm{H}_{2} \mathrm{O}_{2}$, Fenton, and Photo-Fenton is found $69.8 \%, 95.2 \%$, and $93.04 \%$.

- The maximum oil degradation efficiency of artificial wastewater with castor oil for $\mathrm{UV} / \mathrm{H}_{2} \mathrm{O}_{2}$, Fenton, and Photo-Fenton is found at $32 \%, 94.5 \%$, and $83.8 \%$.

- The maximum oil degradation efficiency of artificial wastewater with coconut oil for $\mathrm{UV} / \mathrm{H}_{2} \mathrm{O}_{2}$, Fenton, and Photo-Fenton is found at $23.25 \%, 57.5 \%$, and $61.7 \%$.

- The maximum oil degradation efficiency of real wastewater obtained from Al- Rasheed Vegetable Oil Factory for $\mathrm{UV} / \mathrm{H}_{2} \mathrm{O}_{2}$, Fenton, and Photo-Fenton is found $44.7 \%, 89.2 \%$, and $45.5 \%$.

\section{Acknowledgments}

We would like to thank the technical support of Sanitary laboratory of the Environmental Engineering Department, Al-Mustansiriyah University, and everyone who contributed with information and scientific and ethical effort during this work, with special thanks to "AF" for everything that has gone and continues...

\section{Conflict of Interest}

There is no offense or conflict of interest in the event of publishing this research and study except for the benefit from the study.

\section{Abbreviations \\ AOPs Advanced oxidation processes \\ COD chemical oxygen demand}

\section{References}

1. Mehmet A. O. and Jean A. (2014). A Review Advanced Oxidation Processes in Water / Wastewater Treatment. International Journal of Environmental Science and Technology, (July 2017).

2. Glaze, W. H., Kang, J. W., and Chapin, D. H. (1987). The chemistry of water treatment processes involving ozone, hydrogen peroxide, and ultraviolet radiation. Ozone Sci. Eng., 9(4), 335-352.

3. Andreozzi, R., Caprio, V., Insola, A., and Marotta, R. (1999). Advanced oxidation processes (AOP) for water purification and recovery. Catal. Today, 53(1), 51-59.

4. Zaviska, F., Drogui, P., Mercier, G., and Blais, J. F. (2009). Proceeds oxidations ' advanced treatment des beaux des effluents industrials: Application' a' la degradation des pollutants refractories. Rev. Sci. Eau, 22(4), 535-564.

5. Tarr, M. A. (2003). Chemical degradation methods for wastes and pollutants: Environmental and industrial applications. New York, NY: Marcel Dekker.

6. Tahir, A. H. F. (2016) 'Removal of Vegetable Oil from Wastewater by PhotoFenton,20 (03), pp. 36-46.

7. Chiu, Kuang-ping, Dennis A. Lyn, Philippe Savoye and Ernest R. Blatchley (1999). "Effect of UV System Modifications on Disinfection Performance" Journal of 
Environmental Engineering, ASCE, Vol. 125(5), p. 459-469.

8. Sara A. O. Galvão, André L. N. Mota, Douglas N. Silva, José E. F. Moraes, Cláudio A. O. Nascimento, and Osvaldo Chiavone-Filho, (2006). "Application of the photo-Fenton process to the treatment of wastewaters contaminated with diesel". Sci. Total Environ., vol. 367, no. 1, pp. 4249.

9. Elvana Cako, Kumaravel D. Gunasekaran, Reza. D., Cheshmeh Soltani, and Grzegorz. Boczkaj, (2020). "Ultrafast degradation of brilliant cresyl blue under hydrodynamic cavitation based advanced oxidation processes (AOPs)". Water Resour. Ind., vol. 24, no. August.

10. Mustafa, Y. A. (2013). "Removal of Oil from Wastewater by Advanced Oxidation Process / Homogeneous Process", 19(6).

11. Ibrahim G. A. Rashed, M. A. Hanna, and F. Wali, (2004). "Application of Chemical Oxidation Technology for Treating Industrial Wastewater Containing High Concentrations of Phenol, ”.no. June.

12. Ebrahim, M., Mustafa Y. A., Alwared A. I. (2013)."Removal of oil wastewater by advanced oxidation process/homogenous process". Journal of Engineering, Vol.19, No. 6.

13. Aola, H. F. (2016). "Removaol of Vegetable Oil from wastewater by PhotoFenton". vol. 20, no. 03, pp. 36-46.

$$
\begin{aligned}
& \text { Appendix }-\mathrm{A} \\
& \mathrm{V}_{1} \times \mathrm{C}_{1}=\mathrm{V}_{2} \times \mathrm{C}_{2} \\
& \% \text { Efficiency }=\frac{\text { CODinitial-CoDfinal }}{\text { CODinitial }} * 100
\end{aligned}
$$

